\title{
Mechanical Properties of Concrete Made with Electric Wires, Steel Fibers, Basalt Fibers and Polypropylene Fibers
}

\author{
Yasmin Zuhair Murad \\ y.murad@ju.edu.jo \\ University of Jordan, Amman, Jordan \\ Haneen Abdel-Jabbar \\ eng.haneen.20@hotmail.com \\ University of Jordan, Amman, Jordan
}

\begin{abstract}
An experimental program is conducted in this research to investigate the mechanical properties of concrete made with electric wires, steel fibers, basalt fibers, and polypropylene fibers. Fibers are added to the concrete mix in three different percentages $\left(48,32\right.$ and $16 \mathrm{~kg} / \mathrm{m} 3$ for steel and wire fibers) and $\left(2,4\right.$ and $8 \mathrm{~kg} / \mathrm{m}^{3}$ for basalt and polypropylene fibers). Fifty two concrete cylinders are tested under compression and splitting tensile strength tests to investigate the compressive and tensile behaviors of the fibrous concrete. Test results have shown that steel fiber is superior over the other types of fibers in increasing the compressive and tensile strengths of concrete. The addition of $48 \mathrm{~kg} / \mathrm{m} 3$ steel fiber has increased the compressive strength of concrete up to $9 \%$ and has duplicated its tensile strength compared to the control specimen. The addition of $2 \mathrm{~kg} /$ $\mathrm{m} 3$ polypropylene fibers has increased the compressive and tensile strengths of concrete up to $8.6 \%$ and $10.3 \%$ respectively. Increasing the percentage of polypropylene fibers to $8 \mathrm{~kg} / \mathrm{m}^{3}$ has resulted in increasing the tensile strength of concrete up to $22.8 \%$ while it has reduced its compressive strength by $9.6 \%$ compared to the control specimen. The addition of basalt fibers and wire fibers has resulted in decreasing the compressive and tensile strengths of concrete. The maximum reduction in concrete compressive strength is measured with $48 \mathrm{~kg} / \mathrm{m} 3$ wire fibers where concrete compressive strength is reduced by $32.6 \%$. The lowest tensile strength is measured with $8 \mathrm{~kg} / \mathrm{m}^{3}$ basalt fibers where the tensile strength is reduced by $27.7 \%$.
\end{abstract}

Keywords: Concrete mechanical properties; Recycled electric wires; Steel fibers; Basalt fibers and Polypropylene fibers

\section{INTRODUCTION}

Several experimental programs have been recently conducted to investigate the mechanical properties of concrete made with several types and percentages of natural and synthetic fibers. Natural fibers are fibers that found in the nature such as coconut, horse tail etc. while synthetic fibers are prepared by humans such as carbon, glass, steel, and basalt fibers, etc. Few studies have recently investigated the mechanical behavior of concrete made with waste materials such as plastic, iron filling, rubber etc. (Murad, Abu-Haniyi, Alkaraki \& Hamadeh, 2018) have investigated the compressive and tensile behaviors of concrete made with iron fillings. Researchers have shown that steel fibers have limited effect on the compressive strength of concrete (Ou, Tsai, Liu \& Chang, 
2012) while they can reduce the width and quantity of cracks in concrete elements (Amin \& Foster, 2016). The compressive strength of concrete has been increased up to $21.67 \%$ due to the addition of $0.2 \%$ pvc fibers at 28 days (Nidhish \& Arunima S, 2017). Other researchers have sown that the use of $0.8 \%$ of pvc fibers is an optimum percentage and they have also recommended that pvc concrete can be used as an alternative to plain concrete (Varghese \& Boby, 2017). Gull et al. have shown that pvc can enhance the mechanical behavior of concrete (Gull \& Balasubramanian, 2014).

Alnahhal et al. have shown that concrete compressive strength has not been changed due to the addition of basalt fibers (Alnahhal \& Aljidda, 2018). Other researchers have shown that the mechanical properties of concrete has been improved due to the addition of fiber (Jaysing \& Joshi, 2014). Sahoo et al. (Sahoo, Solanki \& Kumar, 2015) have shown that the compressive and tensile strengths of concrete have not been improved due to the addition of polypropylene fibers while they have shown that the addition of steel and polypropylene fibers can improve the concrete tensile strength about $25-100 \%$.

This research investigates the compressive and tensile behavior of concrete made with electric wires, steel fibers, basalt fibers and polypropylene fibers. Fibers are added in three different percentages $(5 \%, 10 \%$ and $15 \%$ for steel and wire fibers) and $(0.6 \%$, $1.3 \%$ and $2.5 \%$ for basalt and polypropylene fibers) of the total cement weight. The research suggests the preferable type and percentage of fibers that can improve the mechanical properties of concrete.

\section{MATERIAL PROPERTIES}

The proportions of the plain concrete mix which used in this research are shown in Table 1 where the compressive and tensile strengths of the plain concrete are $41.7 \mathrm{MPa}$ and 3.4 MPa respectively. Four different types of fibers, shown in Figure 1, are added solely to the concrete mix in three different percentages; (48, 32 and $16 \mathrm{~kg} / \mathrm{m}^{3}$ for steel and wire fibers which equal to $5 \%, 10 \%$ and $15 \%$ fibers of the total cement weight) and $\left(2,4\right.$ and $8 \mathrm{~kg} / \mathrm{m}^{3}$ for basalt and polypropylene fibers which equal to $0.6 \%, 1.3 \%$ and $2.5 \%$ fibers of the total cement weight). The selected percentages are close to the proportions proposed by the manufactures for each type of fiber. It should be noted that copper is removed from the electric wires and then the electric pvc plastic wires are cut into pieces with fixed length of $60 \mathrm{~mm}$. The properties of the utilized fibers are shown in Table 2.

Table 1: Concrete mix proportions

\begin{tabular}{|c|c|}
\hline Materials & Weight $\left(\mathrm{Kg} / \mathrm{m}^{3}\right)$ \\
\hline Cement & 325 \\
\hline Water & 190 \\
\hline Fine aggregate & 1070 \\
\hline Sand & 690 \\
\hline Super - Plasticizer & 1.195 \\
\hline
\end{tabular}


Table 2: Fiber properties

\begin{tabular}{ccccc}
\hline Fiber type & $\begin{array}{c}\text { Length } \\
\mathrm{mm}\end{array}$ & Diameter & Aspect ratio (L/D) & Density g/cm ${ }^{3}$ \\
Steel fiber & 60 & $0.75 \mathrm{~mm}$ & 80 & 7.8 \\
Polypropylene & 54 & $0.80 \mathrm{~mm}$ & 76.5 & 0.91 \\
Basalt & 60 & $22 \mu \mathrm{m}$ & 2727.3 & 2.7 \\
Wires & 60 & $0.75 \mathrm{~mm}$ & 80 & 1.38 \\
\hline
\end{tabular}

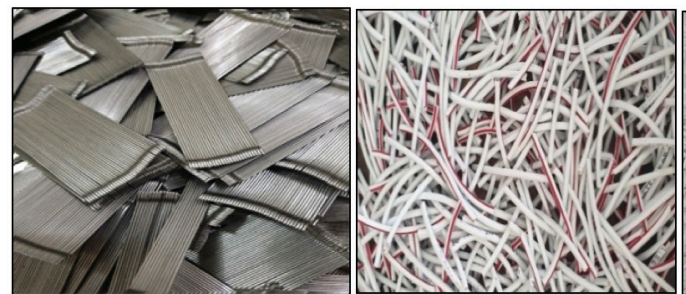

(a) steel fibers

(b) pvc wires

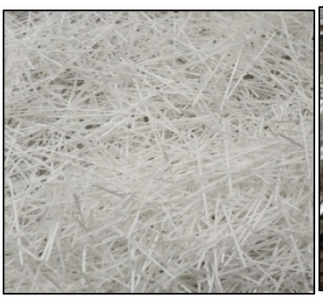

(c) polypropylene

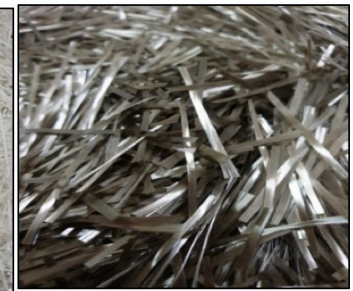

(d) basalt

Figure 1: The utilized fibers

\section{EXPERIMENTAL PROGRAM}

Fifty two cylinders are tested in this research in order to investigate the compressive and tensile behavior of concrete made with electric pvc wires, polypropylene fibers, steel fibers and basalt fibers. Twenty six cylinders are tested under compression strength test while the other twenty six cylinders are tested under splitting tensile strength test. The dimensions of the concrete cylinders are $150 \mathrm{~mm} \times 300 \mathrm{~mm}$. The test setup is shown in Figure 2.

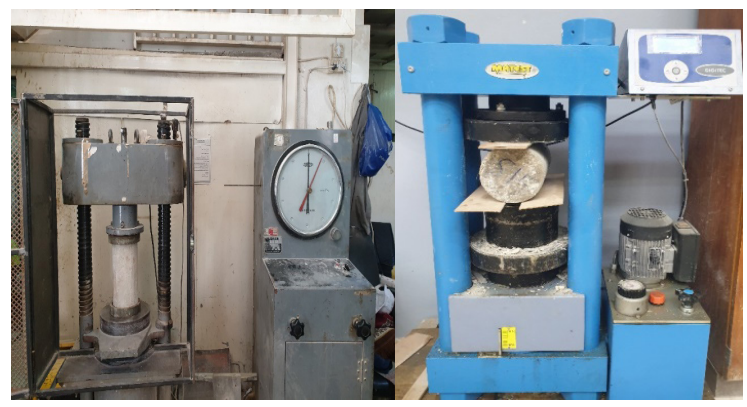

$\begin{array}{ll}\text { (a) Compression test } & \text { (b) splitting tensile test }\end{array}$

Figure 2: Test setup

\section{TEST RESULTS AND DISCUSSION}

Test results are listed in Table 3. Steel fibers and electric wires are added in three different percentages $5 \%, 10 \%$ and $15 \%$ of the total cement weight. The addition of $15 \%$ steel fibers has duplicated the tensile strength of concrete and it has increased its compressive strength up to $8.9 \%$ compared to the control plain concrete. The addition of $5 \%$ and $10 \%$ steel fibers has insignificant effect on the compressive strength of concrete while it has increased its tensile strength up to $59 \%$ and $35 \%$ respectively.

Electric pvc plastic wires are recycled into concrete in three different percentages. 
The addition of wires has an adverse effect on the compressive and tensile strengths of concrete. The addition of $5 \%, 10 \%$ and $15 \%$ wires has reduced the compressive strength of concrete by $15 \%, 19 \%$ and $32.6 \%$ respectively. The tensile strength of concrete is also reduced by $20 \%, 15 \%$ and $25 \%$ due to the addition of $5 \%, 10 \%$ and $15 \%$ wires respectively. A comparison is made between the compressive and tensile strengths of the plain concrete and the concrete made with electric wires and steel fibers as shown in Figure 3 and Figure 4.

Basalt and polypropylene fibers have been added to the concrete mix in three different percentages $0.6 \%, 1.3 \%$ and $2.5 \%$ of the total cement weight. The addition of basalt fibers in any percentage has an adverse effect on the compressive and tensile strengths of concrete. The addition of $2.5 \%$ basalt fibers has reduced the compressive and tensile strength of concrete by $7 \%$ and $27.6 \%$ respectively. Decreasing the percentage of basalt fibers to $5 \%$ and $10 \%$ has reduced the compressive strength of concrete by $12 \%$ and $11 \%$ respectively moreover it has decreased the tensile strength of concrete by $11.6 \%$ and $11 \%$ respectively.

The effect of basalt fibers on the tensile and compressive strengths of concrete is still unclear. Previous experimental results have shown the addition of basalt fibers increased the tensile and compressive strength of concrete while other studies have shown the opposite. Abdulhadi et al. (Abdulhadi, 2014) have shown that the addition of $0.3 \%$ and $0.6 \%$ volume of basalt fiber increased the splitting tensile strength of concrete by $2.6 \%$ and $22.9 \%$ respectively; while the addition of $0.9 \%$ and $1.2 \%$ volume reduced the splitting tensile strength of concrete by $11.3 \%$ and $19.8 \%$ respectively. Sarkar et al. (Sarkar \& Hajihosseini, 2018) have shown that the addition of basalt fiber increased the concrete compressive strength in a range of $4.3 \%$ and $9.4 \%$. Niu et al. (Niu et al., 2019) have shown that the addition of basalt and polypropylene fibers in high percentage has an adverse effect on the mechanical properties of concrete. Gnanasundar et al. (Gnanasundar.V.M \& Palanisamy.T, 2017) have shown that the addition of basalt fiber can increase the strength of concrete when they are added in a low dosage up to $0.3 \%$ of concrete volume, while the addition of high percentage of basalt fibers has resulted in reducing the concrete strength. Murad et al. (Murad \& Abd Aljabbar, 2019) have shown the addition of basalt fibers can increase the flexural strength of RC beams.

Thus, the percentage of basalt fibers has a significant effect on the compressive and tensile strength of concrete. In addition, the mechanical properties of concrete are significantly influenced by the orientation of fibers. In this test, the adopted percentages of basalt fibers are $0.6 \%, 1.3 \%, 2.5 \%$ where the addition of fibers have reduced the compressive and tensile strengths of concrete. Test results agree with the previous results found in the literature.

The addition of polypropylene fibers in any dosage has increased the tensile strength of concrete up to $22.8 \%$ where the maximum enhancement is measured with $2.5 \%$ fibers. The addition of $0.6 \%$ polypropylene fibers has increased the compressive and tensile strength of concrete up to $8.6 \%$ and $10.3 \%$ respectively. The compressive strength of concrete has reduced by $9.6 \%$ and $2.16 \%$ due to the addition of $2.5 \%$ and $1.3 \%$ polypropylene fibers. Figure 5 and Figure 6 compares between the compressive and tensile strengths of concrete made with basalt and polypropylene fibers. 
Table 3: Test results

\begin{tabular}{|c|c|c|c|c|c|c|}
\hline Name & Fiber & $\begin{array}{c}\text { Fiber } \\
\text { weight } \\
\left(\mathrm{Kg} / \mathrm{m}^{3}\right)\end{array}$ & $\begin{array}{c}\text { Average } \\
\text { compressive } \\
\text { strength } \\
(\mathrm{MPa})\end{array}$ & $\begin{array}{c}\text { Increment or } \\
\text { decrement } \\
\text { Fc } \\
\text { percentage } \\
(\%)\end{array}$ & $\begin{array}{c}\text { Average } \\
\text { tensile } \\
\text { strength } \\
(\mathrm{MPa})\end{array}$ & $\begin{array}{c}\text { Increment or } \\
\text { decrement Ft } \\
\text { percentage } \\
(\%)\end{array}$ \\
\hline Control & Control & 0 & 41.7 & & 3.44 & \\
\hline S16 & Steel & 16 & 41.3 & -0.96 & 5.473 & +59.1 \\
\hline S32 & Steel & 32 & 42 & +0.72 & 4.65 & +35.17 \\
\hline S48 & Steel & 48 & 45.4 & +8.9 & 6.909 & +100.8 \\
\hline V16 & Wires & 16 & 35.5 & -14.9 & 2.732 & -20.58 \\
\hline V32 & Wires & 32 & 33.8 & -18.9 & 2.913 & -15.32 \\
\hline V48 & Wires & 48 & 28.1 & -32.6 & 2.577 & -25.08 \\
\hline P2 & Polypropylene & 2 & 45.3 & +8.6 & 3.794 & +10.3 \\
\hline P4 & Polypropylene & 4 & 40.8 & -2.16 & 3.442 & +0.06 \\
\hline P8 & Polypropylene & 8 & 37.7 & -9.6 & 4.225 & +22.8 \\
\hline B2 & Basalt & 2 & 36.6 & -12.2 & 3.042 & -11.6 \\
\hline B4 & Basalt & 4 & 37.3 & -10.55 & 3.058 & -11.1 \\
\hline B8 & Basalt & 8 & 38.7 & -7.19 & 2.489 & -27.65 \\
\hline
\end{tabular}

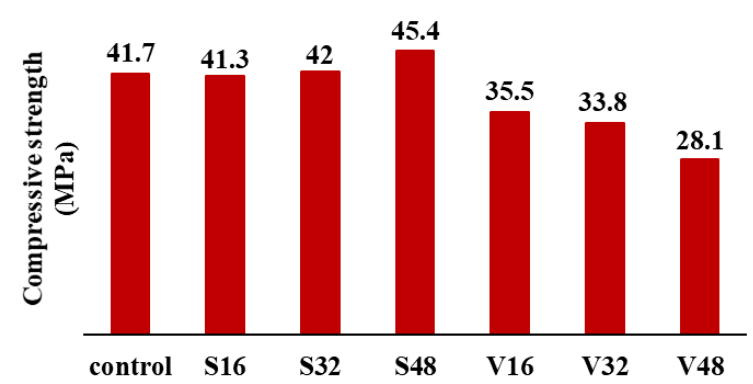

Figure 3: The compressive strength of steel fiber concrete and electric wire concrete

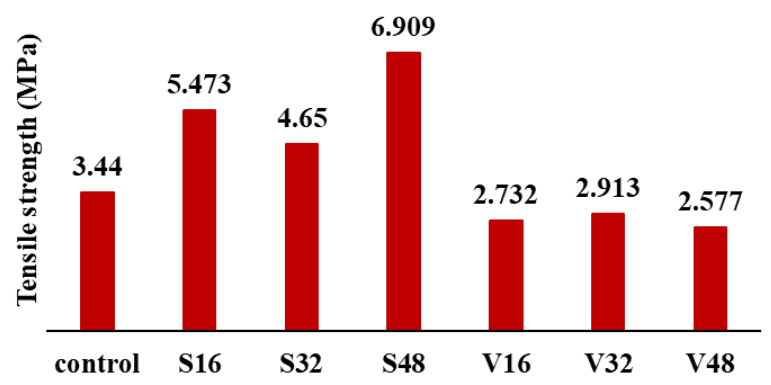

Figure 4: The tensile strength of steel fiber concrete and electric wire concrete 


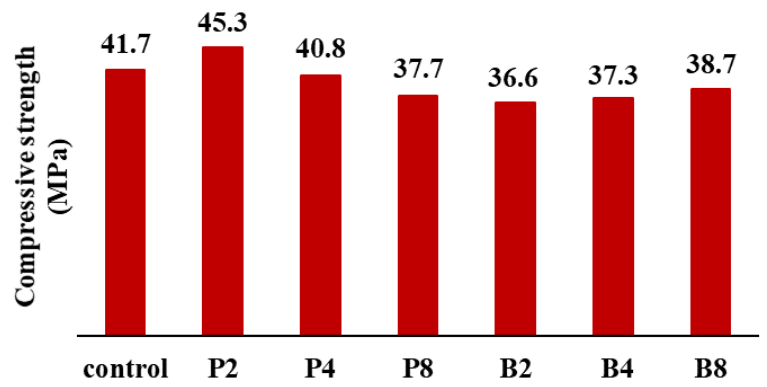

Figure 5: The compressive strength of steel basalt concrete and polypropylene concrete

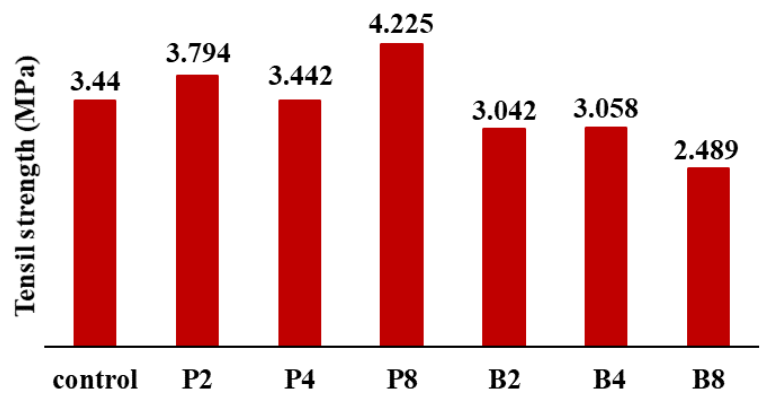

Figure 6: The tensile strength of steel basalt concrete and polypropylene concrete

\section{CONCLUSION}

Fifty two concrete cylinders are tested under compression and splitting tensile strength tests to investigate the compressive and tensile strength of concrete made with electric wires, steel fibers, basalt fibers, and polypropylene fibers. Fibers are added to the concrete mix in three different percentages $(5 \%, 10 \%$ and $15 \%$ for steel and wire fibers) and $(0.6 \%, 1.3 \%$ and $2.5 \%$ for basalt and polypropylene fibers) of the total cement weight. The following points summarize the test results:

- The addition of $15 \%$ steel fibers has duplicated the tensile strength of concrete and it has increased its compressive strength up to $8.9 \%$ compared to the control plain concrete.

- The addition of 5\% and 10\% steel fibers has insignificant effect on the compressive strength of concrete while it has increased its tensile strength up to $59 \%$ and $35 \%$ respectively.

- The addition of wires has an adverse effect on the compressive and tensile strengths of concrete. The addition of 5\%,10\% and $15 \%$ wires has reduced the compressive strength of concrete by $15 \%, 19 \%$ and $32.6 \%$ respectively.

- The tensile strength of concrete is reduced by $20 \%, 15 \%$ and $25 \%$ due to the addition of $5 \%, 10 \%$ and $15 \%$ wires respectively.

- The addition of basalt fibers in any percentage has an adverse effect on the compressive and tensile strength of concrete. 
- The addition of $2.5 \%$ basalt fibers has reduced the compressive and tensile strength of concrete by $7 \%$ and $27.6 \%$ respectively.

- Decreasing the percentage of basalt fibers to $0.6 \%$ and $1.3 \%$ has reduced the compressive strength of concrete by $12 \%$ and $11 \%$ respectively moreover it has decreased the tensile strength of concrete by $11.6 \%$ and $11 \%$ respectively.

- The addition of polypropylene fibers in any dosage has increased the tensile strength of concrete up to $22.8 \%$ where the maximum enhancement is measured with $2.5 \%$ fibers.

- The addition of $0.6 \%$ polypropylene fibers has increased the compressive and tensile strength of concrete up to $8.6 \%$ and $10.3 \%$ respectively.

- The compressive strength of concrete has reduced by $9.6 \%$ and $2.16 \%$ due to the addition of $2.5 \%$ and $1.3 \%$ polypropylene fibers.

\section{REFERENCES}

Abdulhadi, M. (2014). A comparative Study of Basalt and Polypropylene Fibers Reinforced Concrete on Compressive and Tensile Behavior. International Journal of Engineering Trends and Technology (IJETT), 9(6). Lokaliseret fra http://www.ijettjournal.org.

Alnahhal, W. \& Aljidda, O. (2018). Flexural behavior of basalt fiber reinforced concrete beams with recycled concrete coarse aggregates. Construction and Building Materials, 169, s. 165178. DOI: 10.1016/j.conbuildmat.2018.02.135.

Amin, A. \& Foster, S. J. (2016). Shear strength of steel fiber reinforced concrete beams with stirrups. Engineering Structures, 111, s. 323-332. DOI: 10.1016/j.engstruct.2015.12.026.

Gnanasundar, V. M. \& Palanisamy, T. (2017). Evaluation of mechanical properties of basalt fiber reinforced concrete. International Journal of Intellectual Advancements and Research in Engineering Computations, 5(1), s. 857-861. Lokaliseret fra www.ijiarec.com.

Gull, I. \& Balasubramanian, M. M. (2014). A New Paradigm on Experimental Investigation of Concrete for E-Plastic Waste Management. International Journal of Engineering Trends and Technology (IJETT), 10(4). Lokaliseret fra http://www.ijettjournal.org.

Jaysing, G. P. \& Joshi, D. A. (2014). Performance of Basalt Fiber in Concrete. International Journal of Science and Research, 3(5). Lokaliseret fra www.ijsr.net.

Murad, Y. \& Abd Aljabbar, H. (2019). The Influence of Basalt and Steel Fibers on the Flexural Behavior of RC Beams. International Journal of Civil and Environmental Engineering, 13(9), s. 548-551. Lokaliseret fra https://www.researchgate.net/publication/335665848_The_ Influence_of_Basalt_and_Steel_Fibers_on_the_Flexural_Behavior_of_RC_Beams.

Murad, Y., Abu-Haniyi, Y., Alkaraki, A. \& Hamadeh, Z. (2018). An experimental study on cyclic behavior of RC connections using waste materials as cement partial replacement. Canadian Journal of Civil Engineering, 46(6), s. 522-533. DOI: 10.1139/cjce-2018-0555.

Nidhish \& Arunima, S. (2017). Parametric study on fibrous concrete mixture made from e-waste pvc fibers. International Journal of Advance Engineering and Research Development, 4(4).

Niu, D. et al. (2019). Experimental study on mechanical properties and fractal dimension of pore structure of basalt-polypropylene fiber-reinforced concrete. Applied Sciences, 9(8), s. 1602. DOI: 10.3390/app9081602.

Ou, Y.-C., Tsai, M.-S., Liu, K.-Y. \& Chang, K.-C. (2012). Compressive behavior of steel-fiberreinforced concrete with a high reinforcing index. Journal of Materials in Civil Engineering, 
24(2), s. 207-215. DOI: 10.1061/(ASCE)MT.1943-5533.0000372.

Sahoo, D. R., Solanki, A. \& Kumar, A. (2015). Influence of steel and polypropylene fibers on flexural behavior of RC beams. Journal of Materials in Civil Engineering, 27(8). DOI: 10.1061/(ASCE)MT.1943-5533.0001193.

Sarkar, A. \& Hajihosseini, M. (2018). The effect of basalt fiber on the mechanical performance of concrete pavement. Road Materials and Pavement Design. DOI: 10.1080/14680629.2018.1561379.

Varghese, V. M. \& Boby, L. N. (2017). Studies on the effect of fiber size on strength of fibrous concrete mixture made from recycled electronic waste fibers. International Research Journal of Engineering and Technology. Lokaliseret fra www.irjet.net. 